\title{
Radical exenetration of the orbit following traumatic myiasis in a crossbred cow: A case report
}

\author{
Rajesh Kumar Sharma, Madan Lal Sharma, Adarsh Kumar \\ DGCN College of Veterinary and Animal Sciences, CSK HPKV Palampur, India \\ 1.Deputy Director (Retd), Dept. of Animal Husbandry, Govt. of Himachal Pradesh, India \\ Corresponding author: Rajesh K Sharma, email:Rsharmaml@yahoo.com \\ Received: 07-01-2012, Accepted: 18-01-2012, Published Online: 10-03-2012 \\ doi: $10.5455 /$ vetworld.2012.376-377
}

\section{To cite this article :}

Sharma RK, Sharma ML, Kumar A (2012) Radical exenetration of the orbit following traumatic myiasis in a crossbred cow: A case report, Vet World, 5(6): 376-377, doi: 10.5455/vetworld.2012.376-377

\section{Introduction}

The eye is located in the orbital cavity of the skull. It consists of eyeball, optic nerve, and associated structures such as eyelids, conjunctiva, orbital fascia, muscles and lacrimal apparatus [1].The exenetration of orbit is indicated in malignancy or neoplastic growth in the orbit, endophthalmitis or panophthalmitis leading to blindness in the affected eye, trauma or proptosis of the globe and penetrating wounds associated with the protrusion of the ocular contents leading to irreversible damage of the eye, and in suppurative destruction of the eye $[2,3]$.The exenetration procedure involves removal of globe and extra-ocular muscles along with extensive debridement of the para-orbital structures and is a cost effective treatment for a chronic wound infested with maggots [4]. This procedure is effective to safeguard the health of animal when other conservative treatments are not viable alternates. Due to the type of animal rearing practices, particularly in the rural marginal farming conditions, manifestation of a wound by flies is not uncommon. Whilst majority of maggot wounds can be effectively treated using standard conservative treatments; maggot manifestation to an eye wound require immediate attention failing which it can lead to development of severe ocular pathological conditions.

\section{Case history}

A 9 month pregnant crossbred cow aged about 7 years was presented with the history of a chronic maggot wound on the medial canthus of right eye and its treatment at local veterinary institution for about last four months without any progressive healing. The history further revealed continual serosanguinous to exudative lacrimal discharge from the affected eye since the beginning of the condition along with profound inflammation of the orbit. There was history of foul smelling odour in the cow shed. The animal appears to lost vision in the affected eye as it was not able to visualize and feed or water kept on its right side. Animal was diagnosed pregnant at the local veterinary institution at routine three months pregnancy diagnosis protocol.

\section{Treatment}

All the physiological and clinical parameters of the animal were within normal range. Clinical examination revealed a chronic wound near the medial canthus on lower eyelid. The wound was extensively infested with maggots with a very obnoxious odour and protrusion of ocular contents. There was a complete loss of the vision in the affected eye. The affected area was thoroughly cleaned with normal saline solution, maggots were removed using mixture of maggoticidal and antibacterial wound dressing powder (Negasunt ${ }^{\circledR}$; Pfizer Ltd., Germany) in liquid paraffin. Subsequent daily dressing of the wound was done with Neosporin ophthalmic ointment. However, the routine treatment of the infected wound was continued on the protocol mentioned above.

Ten days after parturition, the animal was reexamined. The wound was still present with no evidence of maggots. Considering the chronic nature of the wound with resultant prolapse of ocular contents exenteration of the orbit was decided. The animal was restrained in lateral recumbency with the affected side upwards. Surgical site was aseptically prepared. Analgesia at the site of operation was achieved by performing auriculopalpebral and retrobulbar nerve blocks along with the infiltration of $2 \%$ Lignocaine hydrochloride (Xylocaine, Astra Zeneca Pharma India Limited) at the site of incision. The upper and lower eyelids were stay sutured in continuous fashion and an incision encircling the eyelids was made approximately $0.5 \mathrm{~cm}$ from the margin of the lids, but it was slightly extended on the lower eyelid so as to enclose the affected portion. The eye ball was removed after 
severing the extra ocular muscle and ligation of the optic stump.

The decayed orbital fat and muscles on the inner side of medial canthus were curetted out. The wound was sutured with silk thread No. 1 using horizontal mattress pattern leaving an opening near medial canthus for drainage of exudates and daily insertion of antiseptic impregnated gauze.

Post-operative care included intramuscular injections of procaine penicillin and streptomycin (Dicrystcine$\mathrm{S}^{\circledast}$, Sarabhai Zydus Animal Health Ltd., India) at the rate of $11,000 \mathrm{IU}$ per $\mathrm{kg}$ bodyweight along with meloxicam (Melonex ${ }^{\circledR}$; Intas Pharmaceuticals; India) at a dose rate of $0.3 \mathrm{mg}$ per $\mathrm{kg}$ body weight once daily for 5 days. In addition, pheniramine maleate (Avil ${ }^{\circledast}$, Aventis Pharma Ltd., India) at a dose rate of $1 \mathrm{mg}$ per $\mathrm{kg}$ bodyweight, and a total of $40 \mathrm{mg}$ dexamethasone sodium phosphate (Sandex ${ }^{\circledR}$, Alps Pharmaceuticals, India) intramuscularly once daily for 5 days. The antiseptic dressing of the wound was done daily using mupirocin (Bactroban ${ }^{\circledR}$; Galaxo Smithkline, India) impregnated gauze till healing was complete. The sutures were removed on $12^{\text {th }}$ post-operative day and animal showed uneventful recovery.

\section{Result and Discussion}

The infiltration of maggots to any wound should be immediately checked. In the first instance wound should be cleaned of maggots using maggoticidal drugs and subsequent fly repellents be applied to prevent further infestation. Negasunt can safely be used in the management of maggot infested wounds of certain sensitive areas like eye without any side effect [5].

The chronic traumatic conditions potentially can cause irreparable damage to the organ involved resulting in functional loss. Maggot infestation to a sensitive tissue such as eye can lead to loss of vision if an early treatment could not be achieved. Such conditions can potentially lead to development of severe pathologies and warrants surgical intervention. In such cases exenetration of the orbit is the only viable treatment to prevent further tissue damage and to alleviate discomfort and pain to the animal.

Exenetration of the orbit is a cost effective treatment that helps alleviating traumatic and painful ophthalmic conditions and prevents further damage of the tissue, particularly when restoration of the vision is not possible $[6,7]$, and when conservative treatments are not found helpful. The retrobulbar nerve block for sensory and motor blockade of the orbit and surrounding tissues is generally safe to use with no anesthetic complications and even provide additional benefit of achieving local ocular analgesia [8] and generally also reduce the need of additional postoperative analgesics [9]. However, the infiltration of local anesthesia should be achieved carefully, failing which orbital hemorrhage and injury to the optic nerve can occur. Accidental administration of the local anesthetic into the optic nerve meninges can result in anesthetic complications even to the extent of acute death of the animal [7]. Therefore in such cases, the surgery should be postponed till parturition occurs to facilitate easy restraining without inflicting any injury.

\section{Conclusion}

This article reports the successful management of the wasting chronic affection of the eye unresponsive to the conservative topical treatments along with total loss of vision. The successful outcome of this case suggests that radically exenetration of the orbit is a viable alternate to alleviate the discomfort of the animal and to hasten the recovery in traumatic eye wounds resulting due to chronic maggot infestation.

\section{References}

1. Tyagi R. P. S. and Singh J. (1993). Ruminant Surgery, 1st edition. Delhi: CBS publishers and Distributors, 392.

2. Kumar A. (1996). Veterinary Surgical Techniques, 1st ed., UBS publishers Distributers Ltd, New Delhi pp 205-208.

3. Cullen C. L. and Grahn B. H. (2003). What are your clinical diagnoses, treatment plans, and recommended long-term follow-up for the eyes. Canad. Vet. J., 44: 761-3.

4. Welker B., (1995). Ocular surgery. Vet. Clin. North. Am.: Food Anim. Prac., 11: 149-157.

5. Kumar A., Sharma S. K., Tyagi S. P., Singh, M., Varshney, A. C. and Katoch, R. (2008). Clinical evaluation of negasunt in traumatic myiasis in animals. Ind. J. Vet. Surg., 29:43-44.

6. Vermunt J., (1984). Transpalpebral exenteration in cattle. Vet $Q ., 6: 46-48$.

7. Anderson D. E. and Schulz K. L. (2010). Bovine enucleation: A retrospective study of 53 cases (1998-2006). Canadian Vet. J., 51: 611-614.

8. Accola P. J., Bentley E., Smith L. J., Forrest L. J., Baumel C. A. and Murphy C. J. (2006). Development of a retrobulbar injection technique for ocular surgery and analgesia in dogs. J. Am. Vet. Med. Assoc., 229: 220-5.

9. Myrna K. E., Bentley E. and Smith L. J. (2010). Effectiveness of injection of local anesthetic into the retrobulbar space for postoperative analgesia following eye enucleation in dogs. J. Am. Vet. Med. Assoc., 237: 174-7. 